\title{
Lifestyle Change for Weight Loss in the Inner-City
}

\author{
Chris Feifer ${ }^{1}$, Prapti Upadhyay ${ }^{1}$, and Kristine Potter \\ ${ }^{1}$ University of Southern California
}

\begin{abstract}
In low-income minority communities, there is high prevalence and clustering of obesity, coronary heart disease, dyslipidemia, hypertension and diabetes mellitus. Evidence suggests one way to treat and prevent these conditions is through a very low-fat, high fiber, vegetarian diet. A feasibility study was conducted to determine whether inner-city African American and Latino patients will accept a low-fat vegetarian diet and to assess attitudes about the life-style intervention. Reductions in fat and animal products were acceptable, though complete conversion to vegetarianism was not. Meanwhile, group support was the most highly rated component of the class. Contrary to common perceptions of immigrants needing to maintain traditional habits, the Latino participants enthusiastically adopted new concepts and incorporated new recipes into their diet. Weight loss was achieved during the 8 week course and continued through 18 month follow-up. It appears that individual empowerment through the group intervention, coupled with simple diet messages, supported life-style change in a high-risk group.
\end{abstract}

(C) 2003 Californian Journal of Health Promotion. All rights reserved.

Keywords: Minority Groups, Diet, Obesity, Patient Education

\section{Introduction}

Several studies suggest that the optimal diet for prevention as well as treatment of obesity, dyslipidemia, coronary artery disease, hypertension and diabetes is a very low-fat, high-fiber, vegetarian or near-vegetarian diet (Anderson, Gustafson, Bryant, \& Tietyeb-Clark, 1987; Barnard, 1991; Barnard, Jung, \& Inkeles, 1994; McDougall, Litzau, Haver, Saunders, \& Spillers, 1995; Ornish et al., 1998; Singh, Rastogi, Verma, \& et al, 1992). However, most physicians stop short of prescribing such diets for their patients because they believe that patients will not accept a vegetarian diet or one that is very low in fat. Contrary to this view held by many physicians, several studies indicate that patients can and will accept such diets, both in the short term (Barnard et al., 1994; McDougall et al., 1995) and in the longterm (Anderson et al., 1987; Ornish et al., 1998) subsequently experiencing several positive results, such as improved cholesterol, diabetes control, weight loss, and regression of coronary artery disease. A program for Native Hawaiians promoting low fat traditional foods without calorie restriction demonstrated similar long- term success (Shintani, Beckham, Tang, O'Connor, \& Hughes, 1999). There is nothing in the literature regarding acceptance of such diets in low-income Latino and African American communities in the United States. This paper describes a health intervention program designed for low-income minority patients and its impact on members of these communities.

Los Angeles is home to a diverse population. In the inner-city, residents are predominantly lowincome Latino or African American. Income, race and ethnicity are associated with a higher prevalence of common lifestyle related chronic diseases, and a greater burden of complications and mortality from them.(U.S. Department of Health and Human Services, 2003). The prevalence of diabetes, coronary heart disease, and hypertension, for example, are higher in Hispanics and Blacks than in Non-Hispanic whites (Centers for Disease Control, 2003). These problems are believed to be more aggravated by limited resources in the inner-city for lifestyle change: food choices in restaurants and supermarkets are more limited, opportunities for exercise and healthy recreation 
are scarce, and education classes are difficult to access. Lifestyle and disease management classes offered by some health plans and community agencies remain underutilized by inner-city patients in Los Angeles because patients are often faced with difficulties in accessing classes offered across town or feel compelled to restrict their movement due to safety concerns in certain neighborhoods.

The lack of onsite educational options, and absence of referral resources, prompted faculty from the USC/California Hospital Family Medicine Residency Program to develop the Take Charge class. The course was designed to promote lifestyle change through a group intervention in an overweight, inner-city minority patient population experiencing a variety of lifestyle-influenced chronic diseases. This paper uses a case study to illustrate the health education program.

\section{Methods}

The case study was developed by the course instructors with the assistance of an external researcher using quantitative and qualitative assessments. Information was triangulated to increase the validity of findings.

The course was delivered to 13 cohorts of patients. Weights were collected from cohorts 1 and $2(n=31)$ to measure change before and after the eight week course, as well as at three month follow-up intervals, using one-tailed paired t-tests for significance. Evaluation questionnaires measuring individual perceptions of class content were given to cohorts 4,5 , and 6 on the last day of the course ( $n=34: 25$ Spanish, 9 English). Long-term follow-up phone interviews were also conducted. External interviewers were used to promote honest responses. The follow-up interviews were designed to control for the temporal dimensions of course acceptance and life-style change. Phone interviews were conducted with cohorts $1,2,3$ and $5(\mathrm{n}=49)$. Average time since graduation was 21 months (range $=12-26$ ). Since the course instructors thought there might be an upward bias in graduation-day evaluation responses, the long-term evaluation sample included both graduates and "drop-outs" and analyses compared the responses of each group.

\section{The Lifestyle Change Intervention}

The Take Charge course was developed and facilitated by a Family Physician and a doctor of Public Health. The course consisted of 2-hour sessions held on a weekly basis for eight weeks. Courses were conducted separately in English and Spanish.

California Hospital is home to a Family Medicine residency which operates a primary care Family Practice Center (FPC) across the street from the hospital near the garment district of Los Angeles. For the Take Charge class, faculty members outfitted a large conference room at the FPC, normally used for physician education, with large chairs, some cooking equipment, and educational materials.

FPC patients were referred to the class by their primary care providers. As word of the class spread, patients from neighboring community clinics were also referred. To make the classes more accessible for these outside patients, some sessions were conducted offsite. 124 participants were enrolled in 13 cohorts over four years. The average weight of participants was 237 pounds $(95 \%$ confidence interval $=217$ 258, range $=122-503$ ). This population had multiple related co-morbidities, including: hypertension, coronary artery disease, congestive heart failure, hyperlipidemia, diabetes, arthritis, chronic back pain, depression, and hypothyroidism. Other co-morbidities included: anemia, addiction, blindness, chronic obstructive pulmonary disease, glaucoma, lupus, multiple sclerosis, and seizure disorder.

Participants attending six or more of the eight sessions received graduation certificates. Seventy-four participants graduated and were invited to join alumni activities.

\section{Patient Profile}

Participants in the English language class were primarily African American and ranged from young adults to great grandmothers. A majority of the participants were middle-aged or older and lived alone, while some were raising their 
grandchildren. Many participants were on disability as a result of their weight related comorbidities and spent much of their time alone at home.

Participants in the Spanish language class were more likely to be living in families. Most of them were women with husbands and younger children. A majority were recent immigrants from Mexico or Central America. Although this group was also overweight and had related diseases such as hypertension and diabetes, they were less likely to be as obese as participants in the English language group.

\section{The Class Curriculum}

The curriculum of the Take Charge class was created to reflect the wholistic approach taken by Family Medicine towards patient needs and it emphasized the role of biopsychosocial factors in health. The course curriculum consisted of diet education, fitness exercise, and empowerment and motivational activities. Medical issues related to obesity, such as the relationship between fat and heart disease, were taught by the physician instructor during class discussions. The physician instructor also addressed individual health questions of patients and referred them to their primary care physicians for follow-up as needed.

Participants were instructed to follow a very low-fat, high fiber vegetarian diet, restricting daily fat intake to about 20 grams. The content of the diet education included cooking demonstrations and samples, healthy food displays, and information on shopping, reading labels, and calculating fat and fiber gram intake.

The class devoted time to low impact aerobic exercise, stretching, deep breathing, and meditation relaxation. Empowerment activities designed to enhance self-esteem, raise consciousness, motivate behavior change, and provide support were also regular curriculum features. Active peer support was delivered through group "go-rounds" and a "listening exercise." The focus of the go-rounds was to provide each person time to share with the group and learn about others. The one-on-one listening exercise allowed participants to explore thoughts and feelings with a partner who practiced listening without offering advice. To expand this peer support beyond the classroom, participants were encouraged early in the program to exchange contact information and set up walking dates. As the class progressed, exercises like identifying "10 things I want to do in this lifetime" were incorporated into the Take Charge curriculum to address the deeper motivational needs of participants, especially those on disability who had been out of work for several years. The instructors felt that participants found lifestyle change easier when they were occupied with other lifetime goals and were busy with activities that satisfied them and kept their minds off food. A sample class agenda is provided in Table 1 .

\section{Impact of the Take Charge Course}

Gains in health status were achieved both during the 8 week course and into the second year following class completion (Table 2). The average weight lost during the 8 week course was 4 pounds $(n=16 ; p<0.05$; range $=+5$ to -18 pounds). Longer-term weight loss is available for follow-up periods ranging from 3 months post graduation to 2 years later (mean follow-up period $=11$ months). Using the last known weight as compared to baseline, there was an average 14 pound weight loss $(n=16 ; \mathrm{p}<0.01$; range $=+13$ to -52 ). The ratio of weight reducers to weight gainers during the class period was 2.25:1 and in the follow-up period was 4.3:1. 
Table 1

Sample Class Agenda (9:30-11:30 a.m.)

\begin{tabular}{|l|l|}
\hline \multicolumn{1}{|c|}{ Time } & \multicolumn{1}{c|}{ Event } \\
\hline $9: 30$ & $\begin{array}{l}\text { Group Support: Go-Round, participants report } \\
\text { progress and feelings }\end{array}$ \\
\hline $9: 45$ & $\begin{array}{l}\text { Foods Education: Participants use food labels and } \\
\text { reference book to compare fat grams in "usual" } \\
\text { versus "new substitutes" meals }\end{array}$ \\
\hline $10: 00$ & $\begin{array}{l}\text { Exercise: Warm-up and Low-impact Aerobic } \\
\text { Dancing }\end{array}$ \\
\hline $10: 20$ & $\begin{array}{l}\text { Cooking Demonstration: Greens, Black-eyed Peas } \\
\text { and Hot Water Cornbread }\end{array}$ \\
\hline $10: 40$ & $\begin{array}{l}\text { Discussion/Craft Project: "10 things I want to do } \\
\text { in this lifetime" }\end{array}$ \\
\hline $10: 55$ & One-on-One Support: Listening Exercise \\
\hline $11: 15$ & Relaxation: Deep-breathing \\
\hline $11: 25$ & Closing: Questions and Announcements \\
\hline & \\
\hline
\end{tabular}

Table 2

Changes in Weight

\begin{tabular}{|l|c|}
\hline \multicolumn{1}{|c|}{ Period } & Mean Weight Loss \\
\hline Class Time (8 Weeks) & 4 lbs. $(n=16, p<.05)$ \\
\hline $\begin{array}{l}\text { Follow-Up (Mean=11 months; range=3-18 months } \\
\text { after graduation) }\end{array}$ & $13 \mathrm{lbs} .(\mathrm{n}=16, \mathrm{p}<.01)$ \\
\hline
\end{tabular}

$p$ values are from one-tailed t-tests: paired two sample for means

Group support and food-related content were rated most important by participants in the class. English and Spanish speaking participants ranked support, cooking information, and health information similarly high in importance. Although exercise and relaxation were seen as much less important components of the course, according to long-term follow-up interviews, exercise practices increased following the course. One third of the respondents wanted instruction on exercises appropriate to their disabilities (joint problems, hip pain, pacemaker, use of a cane). Most participants continued using class recipes and techniques for reducing fat.

Drop-outs (attended 2-5 sessions) were surveyed to see whether objections to the class caused their limited attendance. Explanations for low attendance were personal and unrelated to the course. In spite of lower attendance, these participants were able to list concepts they learned from the course and behaviors they changed as a result of their participation.

Take Charge instructors realized early in the course that eating habits of patients did not result from a lack of information but instead reflected larger psychosocial issues. The course was not designed to cure eating disorders, but by combining motivational activities with health education was able to successfully circumvent emotional factors that led to the unhealthy diet choices of many of the patients.

The evaluation interviewers summarized participant response to the intervention as "effusively happy." This satisfaction is credited in large part to empowerment derived from the social support and self-esteem enhancing activities. The instructors credit the wholistic approach of the Take Charge course for impacting the lives of participants beyond its primary aim of encouraging patients to adopt 
healthy diets. For many participants, the class provided the impetus to pursue new careers and fulfill old aspirations, from enrolling in piano classes to starting a home business. Some Alumni members returned to teach subsequent classes, taking over teaching responsibilities from the instructors. The alumni instructors were recruited for their natural leadership and commitment to the class; all had completed high school, some had additional training or education. These alumni instructors served as role models for participants, enhanced the cultural content of the class, and validated the impact of the course, making their involvement invaluable.

\section{Internalization of Diet Concepts}

Although participants reduced their intake of animal products, no one permanently adopted a vegetarian diet as a result of the course. Acceptance of diet concepts was similar among Latino and African American participants. Themes related to acceptance of vegetarianism are listed in Table 3. Decreasing fat through limits on daily fat gram intake, was cited most frequently as the most important thing learned and was one of the behaviors maintained after the program ended.

Table 3

Acceptance of a Vegetarian Diet: Themes from Long-Term Follow-up

\begin{tabular}{|l|l|}
\hline \multicolumn{1}{|c|}{ Theme } & \multicolumn{1}{|c|}{ Findings } \\
\hline Accept Vegetarianism & $\bullet \begin{array}{l}\text { 2 out of 9 participants already considered themselves "not a } \\
\text { meat eater" and found course suggestions easy to adopt. }\end{array}$ \\
\hline Accept Partial Vegetarianism & $\bullet \begin{array}{l}\text { Most participants reported substantial decreases in meat intake } \\
\text { as a result of the class, e.g., "because I was needing to." }\end{array}$ \\
& $\begin{array}{l}\text { All had reduced use of meat and whole eggs but most discussed } \\
\text { the difficulties with which this was accomplished. }\end{array}$ \\
\hline Reject Complete Vegetarianism & $\bullet \begin{array}{l}\text { Complete vegetarianism raised cultural objections. "I am a } \\
\text { black lady, we were raised on meat," and "The Latino is a meat } \\
\text { eater and loves cheese." } \\
\text { Eliminating meat entirely is considered unrealistic, especially } \\
\text { "going cold-turkey" and if "a person has been eating meat all } \\
\text { their life." }\end{array}$ \\
\hline
\end{tabular}

The core foods, legumes, vegetables, and grains, were familiar to the majority of participants, though they had been previously considered by some participants to be "poor foods" that were eaten when one could not afford meat. Several women expressed relief on learning to prepare tasty, nutritious meals without having to focus on meat. Participants also reported that the course provided new ways to cook old foods.

\section{A Comparison of the Spanish and English Language Courses}

The most notable difference between the Spanish and English language courses was the striking industriousness and curiosity of the participants in the Spanish sessions. Their keen interest to expose themselves to new information raised the level of interaction in the class. On the first day of each Take Charge class, participants observed a cooking demonstration and tasted the new, healthier foods. Thereafter, the Spanish courses took on a life of their own with participants exchanging new recipes and bringing food to share with the class on a regular basis although financially, the Spanish language class members were no better off than their English language counterparts. In sharp contrast to the common perception of poorly educated, recent immigrants as clinging to their traditional lifestyles, Latino participants in the Spanish language course enthusiastically adopted the new, healthier methods of cooking to prepare 
traditional recipes and also incorporated American recipes taught in the class into their daily diet. The women came eager to learn and ready to adopt new behaviors. They reported a strong appreciation for the self-esteem content of the class and a desire to protect their children from the problems they had experienced as a result of being overweight. Since these women were responsible for cooking for their families, the changes they made impacted larger numbers of people.

In comparison, the English language courses seemed more complacent. Many expressed a desire to do something with their lives but felt that their health would not permit it, or they worried that doing so would jeopardize their eligibility for disability income. There seemed to be a subgroup with a lower sense of self-efficacy and a greater dependence on the class instructors to help them set targets and meet their goals. Although they were willing to follow instructions and complete home assignments, the participation of this subgroup was more passive.

\section{Discussion}

This case study indicates that the intervention centered on a very low fat, high fiber, vegetarian style of diet was acceptable to inner-city minority patients, with modification. While reductions in animal products are achievable, complete vegetarianism is unrealistic. The wholistic approach was the intervention's greatest strength, coupled with an easy to follow template for reducing fat intake. Participants were successful with behavior changes even in the long-term. The data on weight loss and individual perceptions both provide support for acceptance of the intervention yet indicate that a purely vegetarian diet is not an essential goal.

Weight loss during the class period was less than losses reported in clinical trials; however, weight loss and life-style behaviors continued after the course and reached levels equivalent to other programs (NIH Technology Assessment Conference Panel, 1992; Shape up America \& American Obesity Association, 1996; Wing \& Anglin, 1996). This finding must be treated with caution; self-selection bias limit the conclusions we can draw about the efficacy of Take Charge. Future studies of the class method in this population would need a randomized, controlled design to evaluate whether the intervention reliably results in measurable behavior change and physical outcomes.

Health service experts are calling for redesigned services to achieve better outcomes with chronic disease prevention and management (Etzwiler, 1997; Institute of Medicine, 2001; Wagner et al., 2001). Further research is also needed to evaluate the importance of the different Take Charge curriculum components in achieving desired results. For example, can similar programs be successful without the time devoted to support and patient empowerment? It is important to discern the minimum necessary components so that inexpensive but effective educational programs can be implemented in health care organizations and high risk communities to support the life-style goals of patients and their providers.

\section{References}

Anderson, J., Gustafson, N., Bryant, C., \& Tietyeb-Clark, J. (1987). Dietary fiber and diabetes: A comprehensive review and practical application. Journal of the American Dietetic Association, 87, 1189-1197.

Barnard, R. (1991). Effects of life-style modification on serum lipids. Archives of Internal Medicine, 151, 1389-1394.

Barnard, R., Jung, T., \& Inkeles, S. (1994). Diet and exercise in the treatment of NIDDM: The need for early emphasis. Diabetes Care, 17, 1469-1472.

Centers for Disease Control. (2003, 1/16/2003). Fast stats. Retrieved August 29, 2003, from http://www.cdc.gov/nchs/fastats/Default.htm.

Etzwiler, D. D. (1997). Chronic care: A need in search of a system. Diabetes Educator, 23, 569-573. 
Institute of Medicine. (2001). Crossing the quality chasm: A new health system for the 21 st Century. Washington, DC: National Academy Press (Institute of Medicine - Committee on Health Care Quality in America).

McDougall, J., Litzau, K., Haver, E., Saunders, V., \& Spillers, G. (1995). Rapid reduction of serum cholesterol and blood pressure by a twelve-day, very low fat, strictly vegetarian diet. Journal of the American College of Nutrition, 14, 491-496.

NIH Technology Assessment Conference Panel. (1992). Methods for voluntary weight loss and control. Annals of Internal Medicine, 116, 942-949.

Ornish, D., Scherwitz, L., Billings, J., Gould, K., Merritt, T., Sparler, S., \& et al. (1998). Intensive lifestyle changes for reversal of coronary heart disease. Journal of the American Medical Association, 280, 2001-2007.

Shape up America, \& American Obesity Association. (1996). Guidance for the treatment of adult obesity. Bethesda, MD: Shape Up America!

Shintani, T., Beckham, S., Tang, J., O'Connor, H., \& Hughes, C. (1999). Waianae diet program: Longterm follow-up. Hawaii Medical Journal, 58, 117-122.

Singh, R., Rastogi, S., Verma, R., \& et al. (1992). Randomised controlled trial of cardioprotective diet in patients with recent acute myocardial infarction: results of one year follow-up. British Medical Journal, 304, 1015-1019.

U.S. Department of Health and Human Services. (2003, 2/13/2003). Closing the gap: Eliminating racial and ethnic disparities in health. Retrieved August 29, 2003, from http://www.omhrc.gov/OMH/sidebar/datastats.htm

Wagner, E. H., Austin, B. T., Davis, C., Hindmarsh, M., Schaefer, J., \& Bonomi, A. (2001). Improving chronic illness care: translating evidence into action. Health Affairs, 20(6), 64-78.

Wing, R., \& Anglin, K. (1996). Effectiveness of a behavioral weight control program for blacks and whites with NIDDM. Diabetes Care, 19, 409-413.

\author{
Author Information \\ Chris Feifer, Dr.P.H.* \\ Department of Family Medicine \\ Keck School of Medicine \\ University of Southern California \\ 1000 S Fremont Ave., Bldg A7, Rm 7419 \\ Alhambra, CA 91803 \\ Tel: $617-457-4238$ \\ Fax: 617-457-5858 \\ Email: feifer@usc.edu \\ Prapti Upadhyay, M.A. \\ Department of Family Medicine \\ Keck School of Medicine \\ University of Southern California \\ Kristine Potter, M.D. \\ Los Angeles, CA
}

